\title{
Fundamentación pastoral-educativa para la vida: aportes desde el Documento de Aparecida
}

\author{
Fundamentação da Pastoral Educativa para a vida: \\ aportes desde o Documento de Aparecida
}

\begin{abstract}
José Arlés Gómez Arévalo
Posdoctor en Ciencia y Narrativa, Doctor en Teologia Urbaniana, docente del Doctorado en Educación y colaborador de ITEPAL, Bogotá - Colombia, e-mail: angel777abc@hotmail.com
\end{abstract}

\section{Resumen}

El presente documento, pretende ser un aporte a la reflexión sobre el sentido de la vida, la conciliación y la paz en el contexto pastoral-educativo, desde el Documento Conclusivo de la V Conferencia de Aparecida. Las categorías emergentes en el desarroIlo del mismo Documento, indican la riqueza de este importante encuentro eclesial que significó no pocos contratiempos y dificultades que contribuyeron a fundamentar el sentido y misión de la educación y la pastoral de la Iglesia Latinoamericana y caribeña, en los inicios de este tercer milenio. En efecto, no fue fácil organizar la V Conferencia de Aparecida. La primera idea de realizarla correspondió al arzobispo de Tegucigalpa, cardenal Andrés Rodríguez Madariaga, quien en 2001 propuso que se realizara una nueva conferencia general del episcopado latinoamericano en 2005, al cumplirse 50 años de la primera conferencia y de la fundación del CELAM (consejo episcopal latinoamericano); cuyo origen se debió en gran parte al fallecido obispo chileno Manuel 
Larraín. Una de las razones invocadas por el cardenal hondureño señalaba "la necesidad de retomar las esperanzas del Concilio, con más conciencia de las dificultades que necesitan ser enfrentadas con decisión". Por otro lado, algunos sectores vinculados a la curia del Vaticano pensaban que una actividad como ésta era innecesaria, dado que el Papa Juan Pablo II había tomado la iniciativa de realizar un Sínodo de América, en 1997, y que esto parecía desautorizar la continuidad de las conferencias propias de América Latina. Sin embargo, el cardenal chileno Francisco Javier Errázuriz, jugó en este intento un papel preponderante. Hizo una consulta a las 22 conferencias episcopales de América Latina y el Caribe, y 20 de ellas se manifestaron favorables a la realización de una nueva conferencia general. Consultó igualmente a los 30 cardenales latinoamericanos y 18 de ellos se mostraron de acuerdo. Estos datos terminaron por convencer al Papa Juan Pablo.

Palabras-clave: Educación. Iglesia. Compromiso. Jesucristo. Discípulos misioneros.

\section{Resumo}

Este documento visa a contribuir para a reflexão sobre o sentido da vida, da conciliação e da paz no âmbito pastoral e educacional, a partir do documento de encerramento da $V$ Conferência de Aparecida. As categorias emergentes no desenvolvimento do documento indicam a riqueza desse importante evento eclesiástico que significou não poucos contratempos e dificuldades que contribuíram para embasar o sentido e a missão da educação e da pastoral da Igreja na América Latina e Caribe, no início deste terceiro milênio. Na verdade, não foi fácil organizar a $V$ Conferência de Aparecida. A primeira ideia quanto a fazê-la correspondeu ao Arcebispo de Tegucigalpa, Cardeal Andrés Rodríguez Maradiaga, que, em 2001, propôs a realização de uma nova Conferência Geral do Episcopado Latino-Americano em 2005 para comemoração dos 50 anos da primeira conferência e da fundação do CELAM (Conselho Episcopal Latino-Americano) cuja origem foi, em grande parte, o saudoso Dom Manuel Larraín, do Chile. Um dos motivos citados pelo cardeal hondurenho observou "a necessidade de retomar as esperanças do Conselho, com mais consciência das dificuldades que precisam ser enfrentadas de frente". Por outro lado, alguns setores ligados à Cúria do Vaticano, pensaram uma atividade como esta não era necessária, considerando que o Papa João Paulo II havia tomado a iniciativa de realizar um Sínodo da América, em 1997, e isso parecia desaprovar a continuidade de conferências próprias da América Latina. No entanto, o cardeal chileno Francisco Javier Errázuriz desempenhou um papel fundamental 
nessa iniciativa. Fez uma consulta às 22 conferências episcopais da América Latina e no Caribe, e 20 delas foram a favor da realização de uma nova conferência geral. Também consultou os 30 cardeais latinoamericanos e 18 deles concordaram. Estes dados eventualmente acabaram por convencer o Papa João Paulo II.

Palavras-chave: Educação. Igreja. Compromisso. Jesus Cristo. Discípulos em missão.

Llamados a ser discípulos y misioneros de Jesucristo, Camino, Verdad y Vida, para que nuestros pueblos tengan vida en Él (Jn 14,6).

\section{Introducción}

El términos generales, se puede afirmar que el ser y quehacer del educador cristiano, del teólogo ${ }^{1}$, del intelectual y del agente de pastoral hoy en Latinoamérica y el Caribe, necesariamente deben ser vistos y cuestionados a la luz del Documento Conclusivo (DC) de Aparecida. Desde el planteamiento del mismo método teológico-pastoral que reflexiona y articula desde la fe toda la realidad del pueblo latinoamericano y caribeño, que parte desde un análisis inductivo desde "la base", tratando de conocer

1 Es importante recordar cómo la teología, nace inmersa y determinada por los contextos histórico-culturales. Nace ya contextual y no tiene posibilidad de no serlo. Es fruto de un feliz encuentro entre la antropología hebrea y la filosofía griega. Con esa reflexión y ese discurso el teólogo cristiano conseguirá penetrar en las diferentes culturas, expresarse a sí mismo y expresar el misterio que lo configura, ser recibido y entendido en los diferentes contextos culturales. Se convierte no solamente en la religión de unos pocos, sino de muchos y ha adquirido un cariz de fuerza civilizatoria, sin el cual la historia de Occidente hoy no sería comprensible. Sin embargo, los contextos cambian y se reconfiguran y la teología está llamada a acompañar ese proceso vivo y cambiante, a fin de poder seguir siendo entendida en diferentes contextos y culturas y seguir respondiendo a las preguntas de los hombres y mujeres de ayer y de hoy. La teología hecha en América latina ganó mundo y fue discutida favorable o negativamente, aunque siempre con interés. Provocó respeto en Europa y en los Estados Unidos. Y aquí en el continente ganó credibilidad junto a las bases, a los movimientos populares, a otras fuerzas que no siendo eclesiales encontraban lenguaje e ideales comunes al comprometerse con las luchas de los más pobres. 
y analizar la realidad en toda su complejidad, para, emitir posteriormente, juicios y criterios de discernimiento sobre esa misma realidad.

El DC, deja clara la total disponibilidad de la Iglesia para abrir nuevos caminos de diálogo con el hombre y con la sociedad latinoamericana y caribeña de hoy. Por ello, el mismo método de "Ver-Juzgar-Actuar", que había sido utilizado por los Obispos en Medellín y en Puebla, y quizás había sido algo relegado en el Documento de Santo Domingo, vuelve con todo su dinamismo metodológico a iluminar el trabajo pastoral y teológico en nuestro continente. En efecto, partiendo de la realidad (ver), para pasar a iluminar esa misma realidad con la Palabra de Dios, (juzgar) y sacar las consecuencias y orientaciones para la praxis pastoral (actuar).

Por otra parte, Desde un análisis crítico y sereno del Documento Conclusivo de Aparecida (DC), es posible esbozar algunas líneas y aproximaciones educativas y pedagógicas que pueden expresarse en los Proyectos Educativos Institucionales de las Universidades y centros de educación católicas y cristianas en general, en este caso, mediadas por la reflexión sobre el sentido de la vida, la conciliación y la paz, en un país con graves problemas socio-políticos y culturales, en donde siguen siendo afectados de manera más frontal los grupos más vulnerables: campesinos, desplazados, indígenas, afroamericanos y habitantes pobres de las grandes urbes.

Frente a estas problemáticas, las instituciones educativas, están llamadas a liderar procesos permanentes de transformación de las estructuras socio-económicas y políticas que afectan el entorno educativo del país. Además del establecimiento de Foros y Comités Bioéticos para el estudio de casos de Familia, Personas y Vida, y una nueva orientación de las asignaturas biológico-humanistas, el DC, propone la implementación de la llamada "Escuela Misionera", que puede constituirse como tal en una opción válida que ayudaría a pasar los enfoques pastorales desde una "sensibilidad social" a un servicio comprometido con el hombre latinoamericano y caribeño en su realidad compleja y dinámica. En este sentido, los protagonistas directos del quehacer educativo: estudiantes, docentes y administrativos, están llamados a reinterpretar el sentido profundo que tiene la categoría "discipulado misionero" leído desde la realidad de Latinoamérica y del Caribe hoy. 


\section{VER: La realidad Latinoamericana y caribeña: entre la globalización y la pobreza}

Ante una realidad social y cultural latinoamericana y caribeña, extremadamente compleja, la Iglesia, desde el DC, en Aparecida, propone un análisis profundo de su papel y su misión para dar respuestas asertivas a las comunidades creyentes a lo largo y ancho del continente latinoamericano y caribeño, potenciando a su vez, el sentido más profundo de su papel protagónico en los escenarios sociales, culturales, políticos y religiosos actuales.

Algunos teólogos y pastoralistas, incluso hablan de la necesidad de redescubrir una mejor experiencia de comunión que lleve a la Iglesia, como comunidad de fe, a vivir no centrada en tensiones intraeclesiales, sino en la tarea de proclamar el Evangelio, en medio del oleaje del terrorismo, de la violación continua de los derechos humanos, de la pobreza, de la carrera armamentista de algunos países de la región, del secularismo ateo que viene atacando determinados ambientes y sectores de nuestra cultura, haciendo que Dios sea casi un concepto vacío que poco o nada dice a la vida de las personas y de la comunidad humana.

El DC, en Aparecida, hace un análisis crítico y esclarecedor de la realidad latinoamericana y caribeña y de los juicios y criterios que se emiten en relación a los graves problemas socio-económicos, y en concreto, al neo-liberalismo y a la globalización, tal como se expresa en el n. 61:

La globalización es un fenómeno complejo [...] Para una justa valoración de ella, es necesaria una comprensión analítica y diferenciada que permita detectar tanto sus aspectos positivos como negativos...En la globalización, la dinámica del mercado absolutiza la eficacia y la productividad como valores reguladores de todas las relaciones humanas. La globalización, tal y como está configurada actualmente, no es capaz de interpelar y reaccionar en función de valores objetivos que se encuentran más allá del mercado y que constituyen lo más importante de la vida humana: la verdad, la justicia, el amor, y muy especialmente, la dignidad y los derechos de todos, aún de aquellos que viven al margen del propio mercado.

El mismo DC, en el n. 34, es consciente de la novedad de estos los cambios que ha impuesto el mundo de la globalización, a diferencia de los 
ocurridos en otras épocas, en que no existía un alcance global que, con diferencias y matices, afectaban al mundo entero: una globalización, que se convierte en un factor determinante de los cambios en la ciencia y la tecnología, con su capacidad de manipular genéticamente la vida misma de los seres vivos, $y$, con su capacidad de crear una red de comunicaciones de alcance mundial, tanto pública como privada, para interactuar en tiempo real, es decir, con simultaneidad, no obstante las distancias geográficas.

De la misma manera, afirma el DC, con respecto a la globalización y su dinámica de concentración de poder y riqueza, en el DC n. 62:

Conducida por una tendencia que privilegia el lucro y estimula la competencia, la globalización sigue una dinámica de concentración de poder y de riquezas en manos de pocos... lo que produce la exclusión de todos aquellos no suficientemente capacitados e informados, aumentando las desigualdades que marcan tristemente a nuestro continente (DC n. 62).

En la base de una búsqueda de mejores respuestas socio-políticas y económicas, el DC, analiza el tema de la globalización, que excluye a los más pobres entre los pobres. Sobre el tema, afirma:

Una globalización sin solidaridad afecta negativamente a lo sectores más pobres. Ya no se trata, simplemente, del fenómeno de la explotación y opresión, sino de algo nuevo: la exclusión social. Con ella queda afectada, en su misma raíz, la pertenencia a la sociedad en la que se vive, pues ya no se está en ella abajo, en la periferia o sin poder, sino que se está afuera. Los excluidos no son, solamente, "explotados", sino "sobrantes" y "desechables (DC n. 65).

Ante esta situación de exclusión y aumento de la pobreza, la propuesta del DC, es promover una globalización diferente, que esté marcada por la solidaridad, por la justicia y por el respeto a los derechos humanos (DC n. 64).

\section{Discernir los Signos de los tiempos en medio de las contradicciones}

Por otra parte, el DC, hace una importante reflexión sobre la tremenda contradicción que se presenta en Latinoamérica y el caribe, cuando 
se habla de ser portadores del Evangelio y discípulos de Jesucristo, y a la vez se albergan enormes injusticias y absurdas divisiones entre ricos y pobres: un tercio de los habitantes de la región, se encuentran por debajo de la línea de pobreza. La misma Iglesia, se siente interpelada, dice el DC, a discernir los "signos de los tiempos" a la luz del Espíritu Santo, para ponerse al servicio del Reino"(DC n. 33). Los diversos "signos de los tiempos”, interpelan a la misma Iglesia sobre su papel profético al servicio del Reino y de la Vida. En el n. 33, el DC, afirma:

Los pueblos de América Latina y de El Caribe viven hoy una realidad marcada por grandes cambios que afectan profundamente sus vidas. Como discípulos de Jesucristo, nos sentimos interpelados a discernir los "signos de los tiempos”, a la luz del Espíritu Santo, para ponernos al servicio del Reino, anunciado por Jesús, que vino para que todos tengan vida y "para que la tengan en plenitud" (Jn 10,10.; DC n. 33).

Con respecto al fenómeno de la violencia, el DC, afirma que nuestros países se han convertido en focos de verdadera guerra civil urbana. Está muriendo toda una generación, sobre todo de hombres jóvenes y negros. Esto sucede en Brasil, Colombia, Venezuela, Perú y otros. El tema de la paz y del perdón, de la reconciliación, está en el corazón del mensaje evangélico. En Latinoamérica y el Caribe, la violencia, ha alcanzado niveles sin precedentes y se ha transformado en uno de los principales problemas que obstaculiza su desarrollo social, político y cultural. En la región ocurren 140.000 homicidios por año y una de cada tres familias es victima de agresiones criminales (GUERRERO; GAVIRIA, 2007, p. 32).

Las pérdidas de capital humano, ocasionadas por muerte, mutilación o por incapacidad, y los costos originados por atención médica a las víctimas de la violencia alcanzan en muchos países el 5\% del PIB. A esto se le deben sumar los efectos nocivos de la violencia sobre las inversiones tanto nacionales como extranjeras. No es exagerado afirmar que el desarrollo económico de América Latina en el presente siglo dependerá en buena medida de la capacidad y efectividad que se tenga para resolver los problemas que originan la violencia e incrementan los actos terroristas de muchos grupos de delincuentes. 
Para la Iglesia, tanto la violencia como el terrorismo son expresiones de las más brutales formas de deshumanización que hoy perturban la vida de las comunidades latinoamericanas y caribeñas. No deja de ser llamativo que el mismo DC (n. 48. 34), dedica veintisiete numerales a hablar del tema de la violencia: desde el tráfico, violación, servidumbre y acoso sexual de personas, hasta los robos, asaltos y asesinatos que día tras día, acaban con muchas vidas humanas y llenan de dolor y desolación a muchas comunidades y familias de Latinoamérica y del Caribe (DC, n. 78. 45). El DCA, va a recordar sobre este tema de la violencia, que se constituye en un signo de muerte, lo siguiente:

La violencia reviste diversas formas y tiene diversos agentes: el crimen organizado y el narcotráfico, grupos paramilitares, violencia común sobre todo en la periferia de las grandes ciudades, violencia de grupos juveniles y creciente violencia intrafamiliar. Sus causas son múltiples: la idolatría del dinero, el avance de una ideología individualista y utilitarista, el irrespeto a la dignidad de cada persona, el deterioro del tejido social, la corrupción incluso en las fuerzas del orden, y la falta de políticas públicas de equidad social (DC n. 78).

Este panorama bastante duro que plasma el DCA en el numeral anterior, con respecto a la violencia, tristemente se verifica con las cifras oficiales que hablan de cómo los asesinatos selectivos, las masacres, las amenazas, el miedo y la zozobra, el desplazamiento o la migración forzada, han aumentado en los países latinoamericanos y caribeños. Estas formas de violencia constituyen referentes negativos para el normal desarrollo y crecimiento de las familias, especialmente para los niños que pierden sus padres, familiares o amigos o aquellos que quedan con las imágenes de terror en sus memorias (MADARRIAGA, 2002, p. 227).

\section{JUZGAR: En defensa de la Vida y la Justicia ante los signos de muerte}

La Iglesia, en los últimos tiempos, desde sus diversos documentos, ha defendido el derecho a la vida plena de todos los seres humanos y ha procurado defender las expresiones de vida en todos sus niveles y 
momentos coyunturales. La proclamación del Reino de Dios como mensaje de salvación integral, así como de la liberación de todos los signos de muerte que sofocan la vida, lo que implica una opción radical por parte del cristiano a favor de la justicia y la paz: se trata de la proclamación de un Reino escatológico, con una dimensión inmanente y otra trascendente, pues el Reino de Dios se identifica con aquellos que volvieron a nacer del Espíritu y se empeñan en la construcción de una nueva sociedad, justa y solidaria para todos (GNILKA, 1995, p. 34).

En términos del DC, ante la amenaza creciente de la vida y la justicia, como valores supremos del Reino, por parte de diversas expresiones de violencia y terrorismo, los seguidores de Cristo, deben hacer énfasis en crear una "cultura de la paz" que contrarreste los signos de muerte en los pueblos latinoamericanos y caribeños. Es particularmente significativo el n. 543, en donde la voz de los obispos reunidos, se deja sentir fuerte cuando afirman que:

La radicalidad de la violencia sólo se resuelve con la radicalidad del amor redentor. Evangelizar sobre el amor de plena donación, como solución al conflicto, debe ser el eje cultural "radical" de una nueva sociedad. Sólo así el Continente de la esperanza puede llegar a tornarse verdaderamente en el Continente del amor (DC n. 543).

Esta radicalidad en el amor, como parte de la misión continental, propuesta por el papa Benedicto XVI y como forma de respuesta a la radicalidad de la violencia, es un reto enorme para la Iglesia latinoamericana y caribeña, que ha sufrido y continúa sufriendo las consecuencias de la misma, a lo largo y ancho de su propia geografía y de su propia historia. Un caso concreto lo representa el fenómeno de la migración y el desplazamiento forzados. Estos, se constituyen en dos signos de muerte que aquejan igualmente a Latinoamérica y el Caribe.

Es de amplio conocimiento, la preocupación que en los últimos años, han expresado los ámbitos políticos, sociales y los medios de comunicación sobre el tema de las migraciones y el desplazamiento internacionales (ILDIS-FES, 2004, p. 43-45). En el caso latinoamericano y caribeño, este proceso de movilidad, se ha dado prioritariamente de manera intracontinental y con carácter fronterizo, pero durante las tres últimas 
décadas, se ha venido intensificando hacia los centros de desarrollo del primer mundo, como Estados Unidos y Canadá, o hacia los países miembros de bloques regionales como la Unión Europea.

Según datos del CODHES, un promedio de 1.388 personas por día en Latinoamérica y el Caribe, abandonan sus países de origen para no regresar; al mes, 41.670 y unas 500.000 al año, se convierten en emigrantes. CODHES, advierte que en los últimos cinco años, Latinoamérica se ha convertido en la región de mayor crecimiento mundial en tasas migratoria ${ }^{2}$. Es el caso, especialmente, de muchos jóvenes latinoamericanos y caribeños, que participan activamente en los procesos de migración internacional. La forma en que lo hacen y los factores que determinan su participación, sin embargo, combinan situaciones de protagonismo y de vulnerabilidad frente al deseo de obtención de sus metas y logros. En la escala regional, la forma de migración predominante es la que se da entre países limítrofes, con las implicaciones desventajosas en logros educativos e inserción laboral y probablemente un rápido tránsito hacia la vida adulta, en el caso de los miles de jóvenes latinoamericanos y caribeños que migran, buscando un futuro mejor (MARTÍNEZ, 2006, p. 134-140).

En cuanto al desplazamiento, no deja de ser preocupante el caso de Colombia, donde cuatro millones de desplazados por violencia y conflicto armado se han registrado en el término de diez años, hasta el presente. El 55\% del total de dicha población desplazada, es menor de 18 años, es decir, aproximadamente 412.500 niños, los cuales han escapado del campo con sus familias por presiones de diversos actores armados. En el desplazamiento de la población infantil y de la población en general, tienen responsabilidad los actores que protagonizan el conflicto armado

\footnotetext{
2 Universidad de Georgetown, 1.999. Esta investigadora, afirma que la migración latinoamericana, comprende procesos sociales complejos, altamente dinámicos, multifacéticos que afectan y, a su vez, son afectados por condiciones socio-históricas concretas. Agrega que la movilidad de la población tiene que ver tanto con situaciones globales, como con condiciones de los Estados Naciones y de los individuos o grupos que participan de estos procesos de movilización especial. Para aproximarse a una visión completa de la migración y del desplazamiento internacional, es necesario tener en cuenta al menos tres niveles de análisis: La globalización y transnacionalización de los procesos, las condiciones en los países de salida y destino de los migrantes, y el comportamiento de las migraciones a nivel micro social.
}

Rev. Pistis Prax., Teol. Pastor., Curitiba, v. 4, n. 1, p. 215-238, jan./jun. 2012 
interno colombiano y que violan los derechos humanos fundamentales e infringen las normas del derecho internacional humanitario ${ }^{3}$.

Según el DC, en Latinoamérica y el Caribe, la vida se ve amenazada en cualquiera de las anteriores situaciones antes descritas: pobreza, violencia, terrorismo, narcotráfico, desplazamiento, migración forzada y desastres ecológicos; además, se ve amenazada, a través del aborto y la eutanasia, desde la llamada "limpieza social" (ALTIMÍR, 1979, p. 12), aplicada a personas que habitan en las calles de muchas de las capitales de las naciones del continente y la región. Igualmente, desde situaciones de intolerancia, de abandono de muchos niños y jóvenes que deben subsistir en las calles de las grandes urbes latinoamericanas y caribeñas (DC n. 409 y 420), expuestos a diversos peligros; se ve amenazada, desde los enfermos que carecen de la atención básica, especialmente ancianos, pacientes con el VIH y farmacodependientes y desde los detenidos en cárceles inhumanas, las cuales se constituyen en verdaderas escuelas para aprender a delinquir (DC n. 409-420).

Desde estas realidades, que afectan especialmente a los más pobres y vulnerables: indígenas, afroamericanos y campesinos, la misma Iglesia, se compromete a ser la protectora de aquellos que no tienen voz y se alza como la defensora de la vida, en el nombre de Jesús:

La fidelidad a Jesús, nos exige combatir los males que dañan o destruyen la vida, como el aborto, las guerras, el secuestro, la violencia armada, el terrorismo, la explotación sexual y el narcotráfico (DC n. 4, 275-276).

Este combatir los males que destruyen la vida, hace que la Misión continental (DC n. 550-551, 246-248) a la cual ha convocado la Iglesia,

3 Según estudios de la Universidad de Georgetown, 1.999, se afirma que la migración latinoamericana, comprende procesos sociales complejos, altamente dinámicos, multifacéticos que afectan y, a su vez, son afectados por condiciones socio-históricas concretas. Agrega que la movilidad de la población tiene que ver tanto con situaciones globales, como con condiciones de los Estados Naciones y de los individuos o grupos que participan de estos procesos de movilización especial. Para aproximarse a una visión completa de la migración y del desplazamiento internacional, es necesario tener en cuenta al menos tres niveles de análisis: La globalización y transnacionalización de los procesos, las condiciones en los países de salida y destino de los migrantes, y el comportamiento de las migraciones a nivel micro social.

4 El mismo papa Benedicto XVI, hizo la invitación a esta "Misión continental", convocando a todas las fuerzas vivas de Latinoamérica y del Caribe a comprometerse con ella. 
desde el DC, sea una tarea inaplazable, ya que se trata de la reivindicación de la vida misma, tarea a la cual están convocadas todas las fuerzas vivas del pueblo de Dios, que en Latinoamérica y el Caribe, espera con gozo y esperanza, el nuevo anuncio de Jesucristo, camino, verdad y vida.

En síntesis, El DC, ante estas situaciones de violencia y atentado contra los derechos y dignidad de las personas, apunta a crear una cultura de la vida que se traduce en una cultura para la paz y la educación, como eje estructural y necesario, que previene situaciones de conflicto social, resaltando palabras claves para la vida comunitaria como son la tolerancia, la diferencia, el derecho, el respeto, la educación igualitaria y la opción por la justicia.

Por otro lado, al hablar de la posibilidad de crear las condiciones posibles para generar una "cultura de la vida", es igualmente significativo, que el DC, menciona el amor de Dios como experiencia trinitaria, único amor capaz de construir dicha cultura, ya que la misma, escapa a la violencia y al conflicto, a los intereses egoístas y mezquinos, ofreciendo amor y vida para todos:

Este amor supera el amor humano y participa en el amor divino, único eje cultural capaz de construir una cultura de la vida. En el Dios trinidad la diversidad de personas no genera violencia y conflicto, sino que es la misma fuente de amor y de vida (DC n. 543. 243).

Esta posibilidad que se ofrece, a partir de la visión del amor trinitario, de construir una "cultura de la vida", teniendo como referencia la misma fuente de amor y vida que emana de Dios como comunidad de personas, es un aspecto de gran riqueza que ofrece el DCA, ya que con gran seguridad afirma que solamente en Él, las estructuras de violencia que generan una radicalidad de odio y de muerte, se pueden combatir con la radicalidad del amor de Dios, que es plena donación (DC n. 543.243).

En la comunión trinitaria, la Iglesia latinoamericana y caribeña, encuentra el mejor ejemplo de fraternidad, de donación generosa y de ágape gozoso, capaz de suscitar una conversión del corazón y de romper los lazos de la violencia, el egoísmo, la exclusión y la indiferencia humana. En las manos del ser humano, en Latinoamérica y el Caribe, está el afirmar 
la vida en relación con Dios, evitando la destrucción de la misma especie humana y del planeta tierra ${ }^{5}$, haciendo que el continente latinoamericano y la región caribeña, sean la casa común para todos (DC n. 525.236).

\section{Discípulos misioneros desde la categoría "Vida"}

Una vez, visto el compromiso que asume el DC de Aparecida, con respecto a los signos de los tiempos en Latinoamérica y el Caribe, es importante abordar algunas cuestiones pertinentes al tema del Discipulado misionero en el contexto de la llamada Misión Continental, tema del cual se hablará al final de este escrito.

Para iniciar, conviene decir que frente al llamado "mundo postcristiano", término acuñado por Luis González-Carvajal (1993) profesor de la Universidad Pontificia de Salamanca y que hace referencia a las diversas formas de increencia que existen hoy: al avance del ateísmo, a la indiferencia religiosa, la secularización de la sociedad, a la proliferación de nuevos ídolos y el escepticismo e indiferencia, incluso de muchas personas que se denominan "creyentes", el DC en Aparecida, aporta luces para una nueva lectura del compromiso del cristiano hoy en Latinoamérica y el Caribe, desde la categoría "Discípulo misionero".

Algunos teólogos y pastoralistas, concuerdan en decir que la categoría clave del DC es la palabra Vida: encontrar la vida, la vida verdadera. Entorno a él, se trabaja el tema del discipulado de Jesucristo ${ }^{6}$, así como en el compromiso en favor de su palabra y de su presencia. En el DC, se hace una repetida invitación a los cristianos en América Latina y el Caribe, y

5 Algunos científicos y pensadores notables, expresan su preocupación por la acelerada destrucción de la tierra y no excluyen esta posibilidad, de manera total, dadas las problemáticas que afronta actualmente el ser humano: Stephen Hawking (el problema del consumo de energía), Christian de Duve, (la evolución biológica marcha aceleradamente hacia un momento de ruptura), Arnold Toynbe y Eric Howsbawn, (plantean la inviabilidad del planeta si continúa con la contaminación) y James Lovelock, (alerta sobre la ilógica auto-destrucción del hombre en el planeta).

6 El mismo DC, dice que el discípulo de Jesucristo también debe ser "misionero", mensajero del Evangelio. También aquí surge una objeción: ¿es lícito también hoy "evangelizar"? ¿No deberían, más bien, todas las religiones y concepciones del mundo convivir pacíficamente, tratando de hacer juntas lo mejor para la humanidad, cada una a su modo?

Rev. Pistis Prax., Teol. Pastor., Curitiba, v. 4, n. 1, p. 215-238, jan./jun. 2012 
con ellos los de todo el mundo, para que escuchen el llamados ante todo a ser cada vez más "discípulos de Jesucristo", algo que, en el fondo, ya todo cristiano es en virtud del bautismo, lo cual no quita que deba reflexionar sobre la mejor forma de llegar a serlo siempre de manera nueva a través del compromiso con la misma vida.

En efecto, el DC de Aparecida, en su primera parte, denominada "La vida de nuestros pueblos hoy", en el capítulo 2: "Mirada de los discípulos misioneros sobre la realidad", presenta un panorama muy completo sobre la realidad que interpela a quienes desean ser discípulos misioneros hoy en el amplio y complejo panorama de Latinoamérica y el Caribe.

Dicha realidad se refiere a grandes cambios que afectan profundamente la vida de los pueblos de América Latina y de El Caribe, caracterizados por el fenómeno de la globalización. Se habla no tanto de una época de cambio, sino de un cambio de época, con grandes transformaciones en el campo cultural, sociopolítico y económico. En la evangelización, en la catequesis $y$, en general, en la pastoral, persisten también lenguajes poco significativos para la cultura actual, y en particular, para los jóvenes. Muchas veces, los lenguajes utilizados parecieran no tener en cuenta la mutación de los códigos existencialmente relevantes en las sociedades influenciadas por la postmodernidad y marcadas por un amplio pluralismo social y cultural. Los cambios culturales dificultan la transmisión de la Fe por parte de la familia y de la sociedad.

El encuentro con Jesucristo, da origen a la iniciación cristiana, de ello da fe en el DC el n. 243, que habla sobre el "encuentro con Jesucristo":

No se comienza a ser cristiano por una decisión ética o una gran idea, sino por el encuentro con un acontecimiento, con una Persona, que da un nuevo horizonte a la vida y, con ello, una orientación decisiva. Esto es justamente lo que, con presentaciones diferentes, nos han conservado todos los evangelios como el inicio del cristianismo: un encuentro de fe con la persona de Jesús (cf Jn. 1,35-39).

En el DC, este encuentro con Jesucristo no es conocer quién fue, ni sus doctrinas sino un encuentro personal con la Persona de Jesús. En el primer encuentro de los discípulos de Juan Bautista con Jesús, ellos recibieron su invitación personal "vengan y verán” (Jn 1, 39) y después 
de haber estado con Él casi todo el día, pudieron atestiguar diciendo: "hemos encontrado al Mesías" (Jn 1,41). Podemos observar este encuentro personal en el mismo Evangelio de Juan en el caso de la Samaritana (cap. 4), del ciego de nacimiento (cap. 9). En realidad, los cuatro evangelios se refieren al encuentro con el Evangelio vivo, Jesús (SCHNACHENBURG, 1993, p. 12).

En la realidad latinoamericana y caribeña, después de experimentar este encuentro personal con Jesucristo, el discípulo es llamado a transmitir necesariamente a otros el Evangelio vivo. Por eso, San Pablo dice: "si anuncio el Evangelio, no lo hago para gloriarme: al contrario, es para mí una necesidad imperiosa. jAy de mí, si no predicara el Evangelio!" (1 Cor 9,16).

La Iglesia conoce desde siempre la importancia de este encuentro personal con Jesucristo vivo, sin embargo, a la hora de la "nueva evangelización" que se propone llevar a cabo, es fundamental asegurar este encuentro para la iniciación de la vida de un cristiano verdadero. Este encuentro implica un renovarse constantemente por medio del testimonio personal, del anuncio del kerygma y de la acción misionera de la misma Iglesia (CELAM, 2005, p. 45).

Es importe por otra parte, analizar la importancia que le concede el DC al laicado ${ }^{7}$ su identidad en el contexto de la Iglesia latinoamericana y caribeña, especialmente en el contexto de una Iglesia aún signada por el

7 En términos generales, se puede decir que en la década del 90 hubo en Latinoamérica un gran esfuerzo en muchos niveles, para formar laicos, ayudarlos a asumir su papel dentro de la Iglesia, autocomprenderse como productores de los bienes eclesiales y no meros consumidores. Creo que eso llevó a que se multiplicaran los centros de fe y cultura, los centros de formación de laicos y hoy podamos ver muchas vocaciones teológicas laicales, ministerios laicales que con éxito van asumiendo en la comunidad eclesial creciente importancia en el campo de la liturgia, de la espiritualidad, de la reflexión teológica, de la asesoría pastoral, de la coordinación comunitaria, etc. Sin embargo, todavía existen resistencias por parte de significativos sectores del clero y de la Iglesia en general. La novedad del cristiano laico, con su rostro y su papel dentro de la Iglesia y de la sociedad, todavía advierte dificultades. Ahí merecerían un especial capítulo las mujeres que son siempre y necesariamente laicas, ya que no tienen acceso al ministerio ordenado. El laicado espera de la V Conferencia una palabra que aliente su vida y su fe, que lo anime a seguir adelante buscando la vivencia de la santidad sin sentirse rechazado o disminuido porque se le ha asignado la esfera de lo profano y, por lo tanto, no tiene mucho que decir en su Iglesia. Sería importante que la V Conferencia tuviera la osadía de mostrar que obispos, sacerdotes, laicos y religiosos son todos discípulos de Cristo y encuentran la fuente de su discipulado en su mismo Bautismo. 
clericalismo en muchos sectores. El DC de Aparecida, al retomar la visión del Vaticano II, define a los laicos como "los cristianos que están incorporados a Cristo por el bautismo, que forman el pueblo de Dios y participan de las funciones de Cristo: sacerdote, profeta y rey. Ellos realizan, según su condición, la misión de todo el pueblo cristiano en la Iglesia y en el mundo". Son hombres de la Iglesia en el corazón del mundo, y hombres del mundo en el corazón de la Iglesia (DA n. 209).

En esta visión renovada y positiva del DC de Aparecida, se reconoce en los laicos su vocación de discípulos y misioneros de Jesús. Por tanto, de un laico y una laica debe esperarse lo propio de todo seguidor de Jesús de Nazaret: oración, subversión de los falsos valores vigentes en la sociedad, fidelidad a los criterios evangélicos de la vida, amor prioritario y práctico a los pobres, solidaridad, sentido de Iglesia. La misión de los laicos, según el DC de Aparecida, es hacia fuera y hacia dentro de la Iglesia.

Hacia fuera:

Su misión propia y específica se realiza en el mundo, de tal modo que, con su testimonio y su actividad, contribuyan a la transformación de las realidades y la creación de estructuras justas según los criterios del Evangelio" (DA 210).

Hacia dentro:

Los laicos están llamados a participar en la acción pastoral de la Iglesia, primero con el testimonio de su vida y, en segundo lugar, con acciones en el campo de la evangelización, la vida litúrgica y otras formas de apostolado, según las necesidades locales bajo la guía de sus pastores. Ellos estarán dispuestos a abrirles espacios de participación y a confiarles ministerios y responsabilidades en una Iglesia donde todos vivan de manera responsable su compromiso cristiano (DA 211).

Por último, al hablar de la laicidad, en el contexto de los Discípulos Misioneros, según el DC de Aparecida, se debe aclarar que la misma no es 
un carisma de un grupo de gente de la Iglesia, sino que es una característica de toda la Iglesia. Toda la Iglesia ha de ser laica, en el sentido de estar encarnada en el mundo. El primer elemento de la estructura de la vida de Jesús es la encarnación. Encarnación es un modo de estar en la realidad, es decir: capacidad de dejarse afectar por la realidad, talante compasivo ante el sufrimiento construyendo el reino de Dios en la historia que nos encamine hacia una vida animada por la justicia y el amor.

\section{ACTUAR: La Iglesia en Latinoamérica y el caribe como defensora de la Vida}

En el DC de Aparecida, se menciona que la Iglesia, en Latinoamérica y el Caribe, debe ser testimonio de Jesucristo vivo mediante la entrega y la fidelidad al mensaje del Evangelio, en el contexto de un continente y una región caracterizados por grandes retos sociales, económicos, políticos y culturales. El DC, presenta a lo largo de su desarrollo, algunas facetas de la Iglesia como casa y escuela de vida: "Necesitamos que cada comunidad cristiana se convierta en un poderoso centro de irradiación de la vida en Cristo" (DC n. 362. 168). La meta última del encuentro con Jesucristo y del discipulado misionero, dentro del corazón de la Iglesia, es la propuesta de una vida plena que transforme la realidad de todas las personas y de todos los pueblos y comunidades, que a lo largo y ancho del continente latinoamericano y la región caribeña, esperan que ella sea en realidad, una "comunidad de discípulos misioneros" (DC n. 349. 164).

Dentro del modelo eclesiológico que presenta el DC y que permite fundamentar la propuesta de una opción por la vida, se mencionan cuatro ejes que son de capital importancia, para la comprensión del espíritu de renovación y vida que propone el espíritu de la Conferencia Episcopal de Aparecida: La experiencia religiosa, la vivencia comunitaria, la formación bíblico-doctrinal y el compromiso misionero de toda la comunidad (DC n. 226. 188). En el primer elemento, el DCA, insiste en la importancia de que la Iglesia latinoamericana y caribeña, ofrezca a todos los creyentes "un encuentro personal con Jesucristo" (DC n. 226. 108), del cual ya se ha hecho mención anteriormente. En el segundo elemento, se hace hincapié en la experiencia de vida comunitaria, en donde los discípulos misioneros 
se sientan acogidos e incluidos en la experiencia de vida eclesial (DC n. 226b.108). En el tercer elemento, se menciona la importancia de profundizar en la palabra de Dios y en los contenidos de la fe católica (DC n. 226c. 108) y por último, en el cuarto elemento, se hace hincapié en el compromiso misionero de la misma Iglesia (DC n. 226. 108).

Mons. Radrizzani, en su artículo: La Iglesia siembra palabras y las palabras convocan, expresa con respecto al tema de la opción de la Iglesia en el DC de Aparecida, por la vida:

Otro eje fundamental de Aparecida fue y es la opción por la vida para que tengan vida en Jesús. La Iglesia es consciente de que lo más barato hoy es la vida humana. En esta cuestión de la vida - mirando a Latinoamérica - entramos en la cultura del descarte. Hay una nueva Ilustración: el progresismo ahistórico en el que la idea es superior a la realidad. El reduccionismo antropológico lleva a un terrorismo demográfico. Y esto Aparecida lo denuncia (RADRIZZANI, 2007, p. 23).

Al hacer una propuesta desde la defensa de la Vida, la Iglesia como comunidad de amor y esperanza, recobra el papel protagónico que en términos de Latinoamérica y el Caribe, la ha distinguido desde épocas lejanas. La misma, se sigue manifestando como "Una madre que sale al encuentro, una casa acogedora, una escuela permanente de comunión misionera (DC n. 370.171).

Por ello, también menciona el mismo DC, algunos lugares eclesiales que propician dicho encuentro: en la Sagrada Escritura, a través de su estudio y profundización; en la liturgia, de manera especial en la eucaristía y la reconciliación, sacramentos de vida y de encuentro con Jesucristo y los hermanos; en la oración, tanto personal como comunitaria (DC $\mathrm{n}$. 255. 121); en la comunidad viva de fe y en el amor fraterno, cuando desde el perdón, la solidaridad y la unidad, se experimenta la gracia de ser todos en Jesucristo; de manera especial, dice el DCA, está presente, en los pobres, afligidos y enfermos (DC n. 257. 122). De esta manera, el DC, explicita la propuesta de que la Iglesia debe ser una casa común para todos, que anuncia a Jesús como su gran tarea, como el único que puede darle sentido profundo al peregrinar del ser humano en Latinoamérica y el caribe, entre signos de vida y esperanza. 
Según Mons. Felipe Arizmendi Esquivel, obispo de San Cristóbal de las Casas, siendo que la Iglesia no es fin en sí misma sino para Cristo y el pueblo. Haciendo un comentario del n. 14 del DC, dice Mons. Arizmendi:

Aquí está el reto fundamental que afrontamos: mostrar la capacidad de la Iglesia para promover y formar discípulos y misioneros que respondan a la vocación recibida y comuniquen por doquier, por desborde de gratitud y alegría, el don del encuentro con Jesucristo. No tenemos otro tesoro que éste. No tenemos otra dicha ni otra prioridad que ser instrumentos del Espíritu de Dios, en Iglesia, para que Jesucristo sea encontrado, seguido, amado, adorado, anunciado y comunicado a todos, no obstante todas las dificultades y resistencias. Éste es el mejor servicio que la Iglesia tiene que ofrecer a las personas y naciones (DC n. 14).

Considero oportuno, terminar este apartado con una cita del n. 29 del DC de Aparecida, que sintetiza magistralmente lo que se ha expresado:

Conocer a Jesús es el mejor regalo que puede recibir cualquier persona; haberlo encontrado nosotros es lo mejor que nos ha ocurrido en la vida y darlo a conocer con nuestra palabra y obras es nuestro gozo (DC, n. 29).

\section{Hacia una misión continental}

Según la propuesta del DC, La Iglesia en Latinoamérica y el Caribe, debe entrar en la dinámica de una Misión Continental la cual es un tiempo de gracia para la misma Iglesia que peregrina en América Latina y el Caribe. Se trata de un tiempo para tomar conciencia de su auténtica vocación cristiana. Es una Misión permanente, única y variada, que expresa la voluntad de la Iglesia de ser discípula y misionera de Jesucristo para transmitir a los demás la alegría de la fe en el actual proceso de cambio que vive la sociedad en general. Se trata de un "despertar misionero" que contará con la participación activa de las Conferencias Episcopales y de todas las fuerzas vivas de las Iglesias locales - como por ejemplo, las Comunidades Eclesiales de Base-, en modo tal de "poner a la Iglesia en estado permanente de misión" (DC n. 195 y 570). 
La Misión Continental, según el DC, tiene como protagonista al Espíritu Santo (cf. Redemptoris Missio, 21 CONCILIO VATICANO II, 1997) presente en las Conferencias Episcopales y en las Iglesias locales vivas, que tendrán la tarea de proyectar, impulsar y ejecutar dicha Misión. Ésta tendrá frutos en la medida en que sea llevada a cabo por una Iglesia unida, en comunión y corresponsabilidad con todos los miembros del Pueblo de Dios. La comunión es particularmente importante entre los miembros del clero: obispos y presbíteros de una misma conferencia episcopal y diócesis. Los obispos, presbíteros, diáconos, religiosos, religiosas, consagrados, consagradas, jóvenes, laicos y laicas son agentes de la Misión, quienes han de vivir una profunda espiritualidad misionera.

Los agentes han de contar además con una cualificada formación teológica y catequética ${ }^{8}$, la cual debe integrarse armónicamente en los Centros o Institutos de Formación especializados ya existentes o en Centros nuevos a ser creados. Esto ayudará al fomento, seguimiento y discipulado de Cristo en dimensión ecuménica, así muchas personas podrán descubrir a Jesucristo y su proyecto presente en la Iglesia.

Es importante lo que dice el DC de Aparecida, sobre el hecho de pasar de una Iglesia de concepción sacramentalista a una Iglesia formadora en la fe. Para responder a la sed de Dios que tienen muchos hombres y mujeres del continente. Según el P. Leonidas Ortiz, La Misión Continental es el gran desafío de Aparecida y analizando los Ejes iluminadores de Aparecida, se pueden descubrir en el DC, dos líneas de fuerte impacto: "el llamamiento a la vida plena en Jesucristo, el fortalecimiento de la identidad del Discipulado" y las luces que aporta la Iglesia para alcanzar un compromiso desde la vida nueva en Jesucristo.

Por otra parte, conviene recordar que el tercer y último capítulo se titula: "El compromiso misionero en el mundo de hoy", en el que se destaca la dimensión misionera en Aparecida. Y pone de relieve la gran conclusión

\footnotetext{
8 En lo que concierne a la pedagogía de la catequesis en Latinoamérica y el Caribe, se carece aún del necesario discernimiento teológico-pastoral. Después de una acentuación excesiva del valor del método y de las técnicas por parte de algunos, no se atiende aún debidamente a las exigencias y originalidad de la pedagogía propia de la fe. Se cae con facilidad en el dualismo contenido-método con descuido de la finalidad propia de la catequesis
}

Rev. Pistis Prax., Teol. Pastor., Curitiba, v. 4, n. 1, p. 215-238, jan./jun. 2012 
de Aparecida, la misión continental, "ser de nuevo evangelizadores y fieles discípulos, recomenzando desde Cristo”.

La Misión cuenta con el apoyo decisivo de los laicos, llamados a vivir la vocación universal a la santidad y a la misión (cf. Redemptoris Missio, 90) en sus propios ámbitos de familia, relaciones interpersonales, trabajo... En este sentido, la participación de los movimientos eclesiales y de asociaciones laicales, con el dinamismo e ímpetu propios, es fundamental para el éxito de la Misión Continental.

Según el espíritu del DC de Aparecida, en el contexto de la Misión Continental, es importante renovar las estructuras pastorales de las diócesis, parroquias, comunidades eclesiales de base, pequeñas comunidades, en perspectiva misionera para que se redescubra como comunidad atractiva y atrayente. De La misma manera, las personas y clases dirigentes que viven en los diversos espacios sociales, políticos, culturales y económicos de la sociedad latinoamericana y caribeña, deben comprometerse desde sus lugares de interacción. Igualmente el DC, habla de los nuevos areópagos donde Jesucristo está ausente: familias, colegios, universidades, centros de investigación científica, artes, deportes, nuevas tecnologías de comunicación e información. Hacia ellos, de manera especial, deben dirigirse los empeños de esta Misión Continental que ayudará a revitalizar a la misma Iglesia en Latinoamérica y el Caribe.

\section{Conclusiones}

\section{Hacia una opción por la vida plena en Jesucristo}

En síntesis, se puede decir que la opción por la vida nueva en Jesucristo, se convierte en el corazón de la propuesta del DC de Aparecida. El criterio último y definitivo del discípulo misionero, es que a ejemplo de su Maestro, done generosamente su propia vida en la construcción del Reino de la vida, en medio de los signos de violencia, pobreza, soledad, dolor y miseria en que viven millones de seres humanos a lo largo y ancho del continente latinoamericano y la región caribeña. 
Para ello, el discípulo misionero, inmerso en el misterio de la vida nueva en Jesucristo, se ve convocado a definir nuevas opciones que favorezcan la defensa y el cultivo de la vida, en todas sus expresiones: se trata desde una opción por la Vida Plena en Jesucristo, de que el discípulo misionero, abra nuevos caminos de reflexión, diálogo e interacción entre fe-vida, palabra-realidad y entre encuentro-seguimiento, partiendo de su experiencia personal con Jesucristo, en el seno de la Iglesia.

Una vida ya renovada y transformada desde el misterio de Jesucristo, en sus dimensiones trinitaria, histórica y pascual, ayudará a que el discípulo misionero, en el corazón de la Iglesia, pueda con la ayuda de la vida sacramental y la vida comunitaria, anunciar la Buena Nueva de la Vida, desde el llamado a la "Misión continental" ya mencionada anteriormente.

Una opción por la Vida Plena en Jesucristo, ayuda a asimilar el sentido que tiene la vida humana, no sólo desde la figura histórica de Jesucristo, sino desde el encuentro personal con Él. Se trata de un encuentro de fe con la persona de Jesús (Jn 1, 35-39), recordando así, la experiencia de los primeros discípulos (Jn 1,38 ), que son invitados a ir y ver dónde vive el maestro, quedándose finalmente con Él (Jn 1, 39).

De esta manera, el encuentro con Jesucristo, adquiere su sentido más pleno en la misma vida del hombre, porque en Él, el ser humano puede alcanzar su máxima grandeza; en Él y por Él puede alcanzar todos los bienes anhelados y reservados para él; en Él, por Él y con Él, puede alcanzar el pleno despliegue y total realización de su existencia. La vida que Jesucristo promete y comunica, es la vida en total plenitud, y por toda la eternidad. Vida que es participación de la vida resucitada del Reino, a la vez que se constituye en liberación del mal, del pecado, de la muerte, de todo llanto o dolor (Ap 21,4); vida que es participación y comunión de la misma vida y naturaleza divina (2P 1,4), fuente de gozo inefable e inagotable, que culmina en el tiempo de Dios, pero que se ha iniciado ya en el devenir de la historia de Latinoamérica y el Caribe.

Por último, conviene recordar, que en estos momentos históricos, en que asistimos a una pérdida del centro que motiva la acción de muchos cristianos en el seno de la Iglesia, que incluye por supuesto la transformación social y el compromiso político, el encuentro con Jesucristo, Vida Plena, abre la esperanza que nos da la celebración de su misterio, de la 
certeza del triunfo de la vida sobre la muerte que se dio en Él y por Él, y a través de su compromiso histórico a favor del Reino de Dios que es Justicia y Paz, amor y reconciliación.

En la visión de Aparecida, los cristianos están invitados a hacer su aporte en la búsqueda de soluciones, colocándose como su Maestro, al servicio de sus semejantes, buscando en ellos la vida y las oportunidades para que se desarrolle plenamente la Vida Nueva en todas sus manifestaciones.

\section{Referencias}

ALTIMÍR, O. La dimensión de la pobreza en América Latina. Santiago: CEPAL, 1979.

BIBLIA DE JERUSALEN. Madrid: Paulinas, 1989.

CARVAJAL, L. G. Cristianos del Siglo XXI. Barcelona: Editorial Sal Terrae, 1993.

CONCILIO VATICANO II. Documentos completos. Madrid: BAC, 1997.

CONFERENCIA GENERAL DEL EPISCOPADO LATINOAMERICANO Y DEL CARIBE, 5., 2007, Bogotá. Documento conclusivo... Bogotá: Paulinas, 2007. Documento de Aparecida. Disponible en: <http://www.uc.cl/facteo/centromanuellarrain/download/doc_de_aparecida.pdf>. Acceso en: 20 oct. 2011.

CONSELHO EPISCOPAL LATINO-AMERICANO - CELAM. Fundamentos cristocéntricos para una Nueva Evangelización de América Latina. Bogotá: CELAM, 2000.

CONSELHO EPISCOPAL LATINO-AMERICANO - CELAM. Hacia la V Conferencia General del Episcopado Latinoamericano y del Caribe. Discípulos y misioneros de Jesucristo para que nuestros pueblos en Él tengan vida. Documento de Participación, y fichas metodológicas. Bogotá: CELAM, 2005.

CONSELHO EPISCOPAL LATINO-AMERICANO - CELAM. Las Cuatro Conferencias Generales del Episcopado Latinoamericano. Bogotá: Paulinas, 2004. 
GÓMEZ ARÉVALO, J. A.

FUNDACIÓN FRIEDRICH EBERT - FES. INSTITUTO LATINOAMERICANO DE INVESTIGACIONES SOCIALES - ILDIS-FES. La migración y el desplazamiento en Latinoamérica. Quito: Editorial Almagro, 2004.

GNILKA, J. Jesús de Nazaret, mensaje e historia. Barcelona: Herder, 1995.

GONZÁLEZ DE CARDEDAL, O. La soteriología contemporánea. Salmanticensis, v. 36, n. 3, p. 267-317, 1989.

GUERRERO, R.; GAVIRIA, A. Asalto al desarrollo: violencia en América Latina. Washington: Banco Interamericano del Desarrollo, 2007.

MADARRIAGA, O. Hacerse a la mar. Tegucigalpa: Editorial Código, 2002.

MARTINEZ, J. A. El lenguaje correcto en política. Oviedo: Universidad de Oviedo, Imprensa Univ, 2006.

NUEVA BIBLIA DE JERUSALÉN. Bilbao: Desclée de Brouwer, 1987.

SCHNACHENBURG, R. La persona de Jesucristo reflejada en los cuatro evangelios. Barcelona: Herder, 1993.

Recibido: 15/06/2011

Recebido: 15/06/2011

Aprobado: 06/09/2011

Aprovado: 06/09/2011 